\title{
CONHECENDO O PROGRAMA NACIONAL DE FORTALECIMENTO DA AGRICULTURA FAMILIAR (PRONAF): UMA ANÁLISE COMPARATIVA ENTRE A REALIDADE DO ASSENTAMENTO SALETE STROZAK (GUIRATINGA - MT) E A DOS PEQUENOS AGRICULTORES DE FEIRA DE SANTANA - BA.
}

\author{
José Roberto Silva de Souza ${ }^{1}$; Flávia Almeida Pita ${ }^{2}$. \\ 1. Bolsista PROBIC/UEFS, Graduando em Direito, Universidade Estadual de Feira de Santana, e-mail: \\ zerobertomst@gmail.com \\ 2. Orientadora, Departamento de Ciências Sociais Aplicadas, Universidade Estadual de Feira de Santana, e-mail: \\ fa-pita@uol.com.br
}

PALAVRAS-CHAVE: PRONAF; Agricultura Familiar; Produção de Alimentos.

\section{INTRODUÇÃO}

A investigação propõe a analisar comparativamente os efeitos que o Programa Nacional de Fortalecimento da agricultura Familiar (PRONAF) tem ocasionado no assentamento Salete Strozak, em Mato Grosso, e em uma das comunidades de pequenos agricultores da região de Feira de Santana.

O objetivo é levantar e sistematizar informações sobre os aspectos jurídicos e relevância social do PRONAF, estabelecendo uma ponte com a realidade de sua implementação.

A partir da comparação, tentar-se-á compreender as dificuldades enfrentadas pelos agricultores em acessar o PRONAF, identificar vantagens e desvantagens de cada realidade estudada, de modo a apontar deficiências e vantagens do Programa, bem como caminhos para adequá-lo à realidade que visa a modificar.

Distinguimos a princípio três grandes modelos de agricultura existentes no Brasil, o agronegócio, a agricultura camponesa e a agricultura familiar. Enxergar esses três diferentes atores é importante para a pesquisa haja vista que iremos nos posicionar sobre as comunidades que aqui serão estudadas, que acreditamos ter em seu perfil características dos modelos de agricultura que aqui indicaremos.

A agricultura camponesa no Brasil, como veremos, sempre foi tratada em segundo plano pelo próprio Estado, ficando sempre à margem das políticas públicas, não considerada como contribuinte do desenvolvimento econômico e social do Brasil.

De maneira geral, podemos dizer que o PRONAF é de certa forma uma resposta do Estado às pressões dos movimentos sociais camponeses do Brasil, tendo como objetivo garantir crédito agrícola aos pequenos produtores.

A pesquisa contribui para que compreendamos com mais profundidade os problemas políticos e sociais que encontramos e enfrentamos no dia-a-dia das comunidades que foram estudadas, pretendendo-se que os resultados da investigação contribuam para transformar a realidade que as famílias vivem.

A situação da agricultura na atualidade e realidade brasileira e o confronto entre camponeses e o agronegócio ou entre a agricultura camponesa e a agricultura capitalista é um fenômeno real, concreto, que precisa ser pesquisado ainda mais. Precisamos estudar como o capital atua nos dias de hoje para submeter a Agricultura à condição da produção capitalista, de modo que sejam criadas alternativas que dêem dignidade aos camponeses.

O PRONAF é um instrumento fundamental para o debate do desenvolvimento rural, pois seu significado para a reprodução social entre os agricultores familiares e camponeses é imprescindível. Ressalta-se, diante da atual conjuntura política e econômica no mundo e em 
nosso país, a necessidade de sua continuidade e, na medida do possível, da ampliação de suas ações.

\section{MATERIAL E MÉTODOS OU METODOLOGIA (ou equivalente)}

Temos um bom levantamento bibliográficos sobre o PRONAF, que procura conhecer a forma de implementação do programa e quem são seus beneficiários. Há também pesquisa documental, pois se está levantando e analisando a legislação que disciplina o programa e outros documentos técnicos relevantes.

São utilizadas informações levantadas nos trabalhos acadêmicos do tempo comunidade apresentados nos semestres anteriores, no percurso das disciplinas realizadas no Curso de Direito, especialmente no que diz respeito aos dados já obtidos junto ao Assentamento Salete Strozak, em Mato Grosso.

A investigação contempla, ainda, a realização de entrevistas com os trabalhadores rurais dos dois espaços geográficos, já tendo sido concluídas as previstas para o assentamento localizado em Mato Grosso. A pesquisa prossegue, no entanto, para a conclusão das entrevistas em Feira de Santana e a análise mais aprofundada dos resultados.

Pretende-se compartilhar com os agricultores familiares o resultado da pesquisa, com a finalidade de conscientizá-los sobre a importância do Programa e sobre as formas de acessá-lo.

\section{RESULTADOS E/OU DISCUSSÃO (ou Análise e discussão dos resultados)}

Dentre as reflexões proporcionadas pela conjunção entre os dados e informações teóricas e as observações empíricas algumas merecem destaque,

Importante esclarecer que a modalidade de crédito que pesquisamos em Mato Grosso é a do PRONAF A investimento, modalidade está direcionada para abertura de assentamento. No caso dos trabalhadores rurais de Feira de Santana a modalidade prevalente é a do PRONAF C.

No caso do assentamento Salete Strozak, todos os entrevistados começaram a participar do programa em 2002. As dificuldades encontradas para acessar o programa foram resolvidas coletivamente, as famílias se organizaram e foram até o banco sempre juntas para resolver problemas que estavam dificultando a liberação dos recursos. Todos aplicaram o recurso em um só projeto, estruturaram os lotes para produção de leite bovino.

Todos os entrevistados afirmam que o recurso para investimento é insuficiente e indicam como dificuldades para o desenvolvimento dos projetos a ausência de estruturas públicas, como estradas por exemplo, que impedem a comercialização dos produtos.

Outro problema enfrentado foi a de que o banco não estava preparado para executar o projeto, a agência não tinha pessoal capacitado para liberar o recurso.

Todos dizem que as formas de pagamento estabelecidas é o que o PRONAF tem de melhor, a renegociação também é um grande atrativo para quem não conseguiu pagar em dia as parcelas.

Os entrevistados relacionam entre os pontos negativos do programa: pouco Dinheiro acessado; não são contempladas todas as demandas da produção; o Banco não está preparado para lidar com o PRONAF; muita exigência documental e burocracia para o acesso ao programa; ausência de acompanhamento técnico e capacitação para os assentados.

$\mathrm{O}$ trabalho aqui desenvolvido pretende contribui com a IEPS-UEFS na sistematização das informações sobre o PRONAF, especialmente no seu objetivo de contribuir para o desenvolvimento local e para a implementação e fortalecimento de políticas públicas voltadas à Economia Popular e Solidária. 
Entende-se que a pesquisa, ainda, oportuniza o real e efetivo relacionamento entre ensino, pesquisa e extensão, bem como um momento de reflexão sobre teoria e prática, percebendo-se a importância da pesquisa acadêmica para transformação da realidade.

Objetiva-se, realizar oficinas e outros momentos de formação com os agricultores familiares acerca do PRONAF.

\section{CONSIDERAÇÕES FINAIS (ou Conclusão)}

O PRONAF, para além de ser um simples programa de crédito disponível para a agricultura familiar, é também um programa que atinge diversos aspectos da vida social das famílias que o acessam.

O impacto causado pelo PRONAF nas vidas dos assentados é referente em sua maior parte ao nível de qualidade de vida, pois aqueles que obtiveram os recursos puderam transformar toda uma estrutura de produção em suas terras garantindo com isso trabalho e renda pra toda a família.

Podemos considerar que o programa é um importante instrumento de distribuição de renda entre os agricultores, pois ele foi projetado para atender sujeitos e famílias que necessitam de ajuda financeira para garantir sua existência enquanto agricultores.

No entanto, por mais que ele pareça ser um recurso destinado a melhorar a qualidade de vida no campo, não podemos concluir que este é uma ferramenta de emancipação dos agricultores, sendo que ele também traz para as famílias que o acessam problemas econômicos desconfortáveis.

E, finalmente, poderíamos aqui dizer que o estudo do impacto do PRONAF nas comunidades que serão estudadas é de grande importância, pois através desse estudo poderemos perceber com mais clareza as dificuldades e problemas enfrentados por elas.

\section{REFERÊNCIAS}

BANCO CENTRAL BRASIL, FAQ - Programa Nacional de Fortalecimento da Agricultura Familiar - Pronaf. Brasília: Banco Central do Brasil, 2013. Disponível em http://www.bcb.gov.br. Acesso em: 28 mar. 2015.

BANCO CENTRAL DO BRASIL, RESOLUÇÃO No 4.298, DE 30 DE DEZEMBRO DE 2013, Brasília, 2013. Disponível em: http://www.bcb.gov.br . Acesso em: 28 mar. 2015.

BENJAMIM, Cesar...[ et. al..]. A opção brasileira. 1. ed. Rio de Janeiro: Contraponto, 1998.

BRASIL. Lei n. 4.504, de 30 de novembro de 1964. Dispõe sobre o Estatuto da Terra, e dá outras providências. Brasília. 1964. Disponível em http://www.planalto.gov.br. Acesso em: em 28 mar. 2015.

CALDART, Roseli Salete. ALENTEJANO, Paulo. (orgs). MST, Universidade e Pesquisa. 1. ed. SãoPaulo: Expressão Popular. 2014.

FARIA, José Eduardo (Org.). REGULAÇÃO, DIREITO E DEMOCRACIA. São Paulo. Editora Fundação Perseu Abramo. 2002.

FERNANDES, Bernardo Mançano. MEDEIROS, Leonilde Servolo de. PAULILO, Maria Ignez. (Orgs.) Lutas camponesas contemporâneas: condições, dilemas e conquistas. O campesinato como sujeito político nas décadas de 1950 a 1980. v.1. São Paulo: UNESP. 2009. 
FURTADO, CELSO. Formação econômica do Brasil. 32.ed. São Paulo: Companhia Editora Nacional. 2005.

GODOI, Emilia Pietrafesa de Menezes. MARILDA, Aparecida de. MARIN, Rosa Azevedo. (Orgs.). Diversidade do campesinato: expressões e categorias Construções identitárias e sociabilidades. v. 1. São Paulo: UNESP. 2009.

GUZMÀN, Eduardo Sevilla. MOLINA, Manuel González de. Sobre a Evolução do Conceito de Campesinato. 3. ed. São Paulo: Expressão Popular. 2005.

MINISTÉRIO DO DESENVOLVIMENTO AGRÁRIO. Plano Safra 2014-2015. Disponível em: http://www.agricultura.gov.br. Acesso em: 28 mar. 2015.28/03/2015.

MORISSAWA, Mitsue. A História da luta pela terra e o MST. São Paulo. Expressão Popular, 2001.

NAVES, Márcio Bilharinho. A Questão do Direito em Marx. 1. ed. São Paulo: Outras Expressões; Dobra Universitária. 2014.

NEVES, Delma Pessanha (Org.). Processos de constituição e reprodução do campesinato no Brasil - Formas dirigidas de constituição do campesinato. v. 2. São Paulo: UNESP. 2008.

OLIVEIRA, Ariovaldo Umbelino de. Modo de Produção Capitalista, Agricultura e Reforma Agrária. 1. ed. São Paulo: FFLCH/Labur Edições. 2007.

QUITANEIRO, Tânia. BARBOSA, Maria Ligia de Oliveira. OLIVEIRA, Márcia Gardênia Monteiro de. Um Toque de Clássicos, 2. ed. Belo Horizonte: UFMG, 2003

SANTOS, Boaventura de Souza. Os conflitos urbanos no Recife: O caso do SKYLAB. Revista Crítica de Ciências Sociais. n. 11, 1983.

SILVA, Roberto Marinho Alves da. A trajetória recente da Economia Solidária no Brasil. Nota Técnica. Brasília: SENAES/TEM, 2010.

STÉDILE, João Pedro. FERNANDES, Bernardo Mançano. Brava Gente: a trajetória do MST e a luta pela terra no Brasil. 3. Reimp. São Paulo. Fundação Perseu Abramo, 2005.

STÉDILE, João Pedro.(Org) A questão agrária no Brasil. O debate na década de 1990. 2. ed. São Paulo:. Expressão Popular. 2013.

STÉDILE, João Pedro.(Org) A Questão Agrária no Brasil: história e natureza das ligas camponesas- 1954-1964. 2. ed. São Paulo: Expressão Popular, 2012.

STÉDILE, João Pedro.(Org). A questão agrária no Brasil. Debate sobre a situação e perspectivas da reforma agrária na década de 2000. 1. ed. São Paulo: Expressão Popular. 2013.

STÉDILE, João Pedro.(Org). A questão agrária no Brasil. O debate na esquerda - 19601980. 2. ed. São Paulo: Expressão Popular. 2012.

WELCH, Clifford A. MALAGODI, Edgard. JOSEFA S. WANDERLEY, Maria de Nazareth B. (Orgs.) Camponeses brasileiros. v. 1. São Paulo: UNESP. 2009.

WOLKMER, Antônio Carlos. Pluralismo Jurídico, Fundamentos de uma nova cultura do Direito. 3. ed. São Paulo: Alfa Omega. 2001. 